\title{
MODELING OF SNOW FLOW
}

\author{
By J. D. Dent and T. E. LANG \\ (Department of Civil Engineering and Engineering Mechanics, Montana State University, \\ Bozeman, Montana 5971 7, U.S.A.)
}

\begin{abstract}
A numerical computer model, based on the finite differencing of the Navier-Stokes fluid equations, is used to simulate snow-avalanche flow. In order to verify and calibrate the numerical model, snow-flow tests $0.20 \mathrm{~m}$ deep with flow velocities between $0-18 \mathrm{~m} / \mathrm{s}$ were conducted. Data concerning position, velocity, and flow depth versus time were collected and compared to model runs on the computer. The frictional force on moving snow is investigated and found to be modeled by a term that is proportional to the square of the flow velocity.
\end{abstract}

RÉsumé. Modélisation de l'écoulement de la neige. Un modèle numérique informatique, basé sur la résolution par les différences finies de l'équation des fluides de Navier-Stokes est utilisée pour simuler l'écoulement d'une avalanche de neige. En vue de vérifier et de calibrer le modèle numérique, on a conduit des expériences d'écoulement de neige sur $0,20 \mathrm{~m}$ de profondeur à $0-18 \mathrm{~m} / \mathrm{s}$. Les données concernant la frontière, la vitesse et la profondeur de l'écoulement en fonction du temps ont été recueillies et comparées aux caractéristiques du modèle sur ordinateur. Les forces de frottement sur la neige en mouvement ont été étudiées et on a trouvé qu'elles étaient représentées par un terme qui est proportionnel au carré de la vitesse de l'écoulement.

Zusammenfassung. Modelle für den Schneefluss. Zur Simulation des Schneeflusses in Lawinen wird ein numerisches Rechnermodell herangezogen, das auf finiter Differenzenbildung mit den Navier-Stokes'schen Gleichungen beruht. Zur Kalibrierung und Kontrolle des numerischen Modell wurden Schneeflusstests mit $0,20 \mathrm{~m}$ Tiefe und $0_{-1} 8 \mathrm{~m} / \mathrm{s}$ Geschwindigkeit durchgeführt. Die gewonnenen Daten über die zeitliche Lage, Geschwindigkeit und Fliesstiefe wurden mit Durchrechnungen des Modells im Computer verglichen. Die Untersuchung der Reibungskraft an bewegtem Schnee zeigt, dass sie sich durch einen zum Quadrat der Fliessgeschwindigkeit proportionalen Ausdruck darstellen lässt.

\section{INTRODUCTION}

The intent in the present work is to formulate an avalanche flow model in the velocity range 0 to $20 \mathrm{~m} / \mathrm{s}$. This model takes the form of a computer code in which snow flow is represented as a transient process based upon the numerical solution of the Navier-Stokes equations. The need to determine a physically based model centers on the application of transient-flow modeling to the problem of avalanche run-out and avalanche impact upon structures.

A numerical computer code, designated SMAC, and developed by Amsden and Harlow (1970) at the Los Alamos Scientific Laboratory was used as the basis for the snow-flow model. SMAC solves the full two-dimensional Navier-Stokes equations for the motion of a linearviscous fluid subject to specified initial and boundary conditions.

Due to the shortage of available data with which to appraise the SMAC calculations, a field test program was initiated. For these tests, volumes of snow of up to $2.7 \mathrm{~m}^{3}$ were accelerated to speeds of $18 \mathrm{~m} / \mathrm{s}$ and then allowed to decelerate to rest on a flat level run-out of packed snow. Leading-edge speeds, depth of flow, and data of velocity versus depth were then measured from $16 \mathrm{~mm}$ movie film of each test. These data were then used for the evaluation of the numerical model.

In the computer model two parameters were varied, the kinematic viscosity, which is treated as it normally appears in the Navier-Stokes equations, and a coefficient associated with a friction force at the base of the flow. Several possible forms of the friction force were investigated, and one made up of two parts (a Coulomb friction term, and a term proportional to the square of the flow velocity) was found to fit the experimental data best. Results for terminal velocity from other tests were used to reduce the friction coefficients to a single parameter. 


\section{SNOW TEST DATA}

The collection of field data on snow motion was made with the intent of using the data for evaluation of the computer model. The objectives of the tests were to reach the highest flow velocities, yet maintain controled flow conditions to simplify analysis.

The field test site was a $30^{\circ}$ slope near the Bridger Bowl Ski Area in south-western Montana. At the bottom of the slope was a flat level run-out area of packed snow. In order to achieve the maximum velocity, a section of the $30^{\circ}$ slope $2 \mathrm{~m}$ wide was lined with a polyethylene plastic sheet. This allowed dumped snow to accelerate with minimal frictional resistance. The test data were then obtained from the deceleration of the snow when it reached the bottom of the slope and exited onto the $2.4 \mathrm{~m}$ wide run-out area of packed snow. Dumping the snow was accomplished by first filling a $\mathrm{I} .2 \mathrm{~m} \times \mathrm{I} .8 \mathrm{~m} \times \mathrm{I} .2 \mathrm{~m}$ deep plywood box with snow that had been sifted through a $6 \mathrm{~mm}$ wire mesh, and then tilting the box to release the snow. Maximum flow velocities of $18 \mathrm{~m} / \mathrm{s}$ were achieved in this way. The test site is shown in Figure $\mathrm{I}$.

Flow data were recorded by filming each event with a $16 \mathrm{~mm}$ movie camera. Most tests were filmed from an exterior position to record flow velocities and depth profiles. However, several tests were filmed from behind a glass window located $2 \mathrm{~m}$ into the run-out area (Fig. 2) in order to record velocity versus depth data.

In the first tests, the dump box was located $30 \mathrm{~m}$ up-slope from the run-out area. In this configuration full dump loads of snow entered the flat run-out area at $12 \mathrm{~m} / \mathrm{s}$, and were $7 \mathrm{~m}$ long and $0.20 \mathrm{~m}$ deep. The snow flowed in the run-out area for $\mathrm{I} .8 \mathrm{~s}$ to a distance of $12.3 \mathrm{~m}$. The position of the leading edge as a function of time and the terminal debris depth distribution were reduced from the $16 \mathrm{~mm}$ film of the test.

A test was also conducted in which the volume of snow dumped was one-half the volume of a full-load test. For this test the velocity at the bottom of the slope was ro $\mathrm{m} / \mathrm{s}$, with the

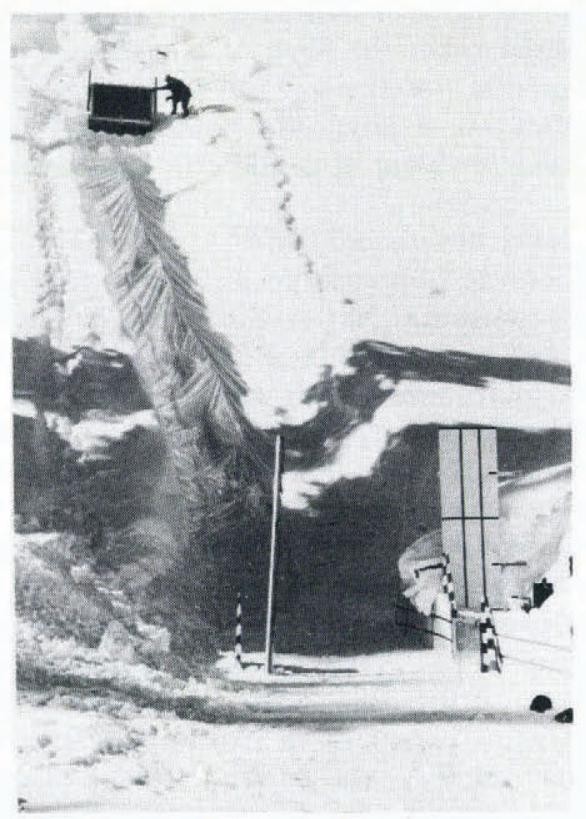

Fig. . . Snow test facility. 


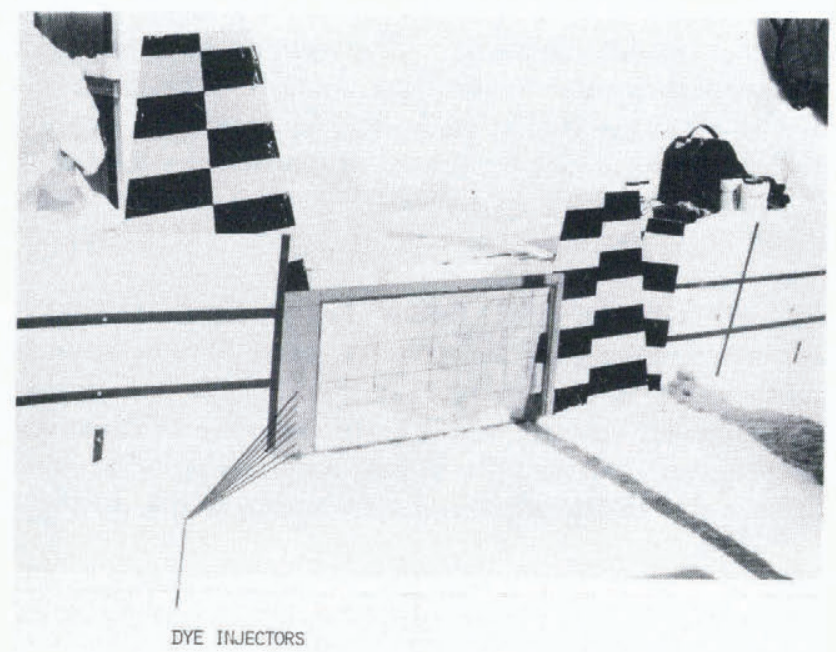

Fig. 2. Glass window used to measure the velocity profile in the run-out area.

flow o. $10 \mathrm{~m}$ deep and again $7 \mathrm{~m}$ long. The flow stopped $9.4 \mathrm{~m}$ into the run-out area after I.5 S. The leading edge position as a function of time and the terminal debris distribution were again deduced from film.

Tests filmed from behind the glass window in the run-out area were conducted with fullload dumps. However, in the course of the previous tests, the plastic sheet lining the slope became torn and the velocity of the snow entering the run-out was reduced to $10 \mathrm{~m} / \mathrm{s}$. In order to make the flow visible, streams of dye were injected into the snow just before reaching the window (see Fig. 2).

To obtain higher velocities, the dump box was moved up-slope an additional $20 \mathrm{~m}$. In this configuration, full-load dumps $\left(2.7 \mathrm{~m}^{3}\right)$ reached a velocity of $18 \mathrm{~m} / \mathrm{s}$ after descending the $50 \mathrm{~m}$ of plastic-lined slope. The dimensions of the flow were again $0.20 \mathrm{~m}$ deep and $7 \mathrm{~m}$ long. The run-out took $2.4 \mathrm{~s}$ with the leading edge traversing a distance of $22.3 \mathrm{~m}$.

A series of tests were also made on a $42^{\circ}$ slope by allowing $1.2 \mathrm{~m} \times \mathrm{I} .8 \mathrm{~m} \times 0.25 \mathrm{~m}$ deep samples of sifted snow to accelerate down a $12 \mathrm{~m}$ packed snow slope. A terminal flow velocity of $6.0 \mathrm{~m} / \mathrm{s}$ and a flow depth of $\mathrm{i} 2 \mathrm{~cm}$ were achieved in these tests. No run-out of the material was recorded.

\section{COMPUTER GODE DESGRIPTION}

The SMAC computer code is based on the solution to the Navier-Stokes fluid equations. These equations describe homogeneous, isotropic, incompressible, linear-viscous fluid flow. Snow is made up of finite discrete particles so it must be assumed that the size of the particles is small compared to the dimensions of the flow. Larger particles and chunks of snow are assumed to be carried along by the motion of the smaller particles. Also, rotational interactions of the snow granules must be neglected. The incompressibility condition is questionable and data concerning density distribution in avalanches is needed. However, in the snow tests, only small variations in the density were measured between the sifted snow before release and the snow after it had come to rest in the run-out area. The assumption of a linear fluid is also an approximation since the shear stress most probably does not vary linearly with the velocity gradient within the moving snow. Linearity is the simplest assumption, and with the lack of data on the rheological properties of snow, a more involved representation appears unwarranted at this time. 
SMAC, which is an acronym for "simplified marker and cell", numerically integrates the full two dimensional Navier-Stokes equations. The equations are put in finite-difference form over a rectangular grid superimposed on the flow domain. The fluid velocities at the center of each of these grid cells are computed at each time increment. Location of the fluid, particularly the fluid surface, is maintained by inserting marker particles into the computational fluid domain. These marker particles are moved according to the calculated velocity in the cell in which they reside. The particles thus ride along with the fluid and serve as a means of identifying the fluid position.

As SMAC was originally written, either free-slip or no-slip tangential boundary conditions were allowed on the walls surrounding the flow domain. These boundary conditions were imposed by specifying the tangential velocity in boundary cells just outside the computational grid. Setting the boundary cell velocity equal to the velocity in the adjoining flow cell gave the free slip condition (Fig. 3a). Giving the boundary cell a velocity equal in magnitude but of opposite sign to the velocity in the adjoining flow cell gave the no-slip condition (Fig. $3 \mathrm{~b}$ ).

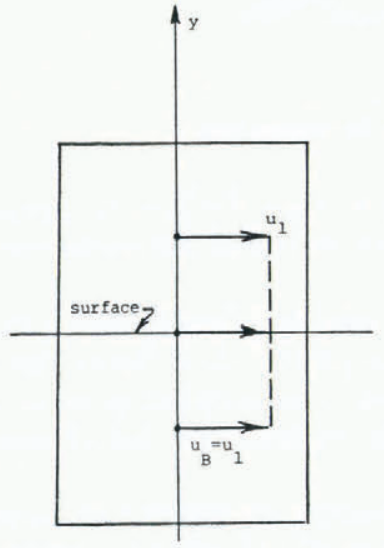

a) FREE SLIP $u_{s}=u_{1}$

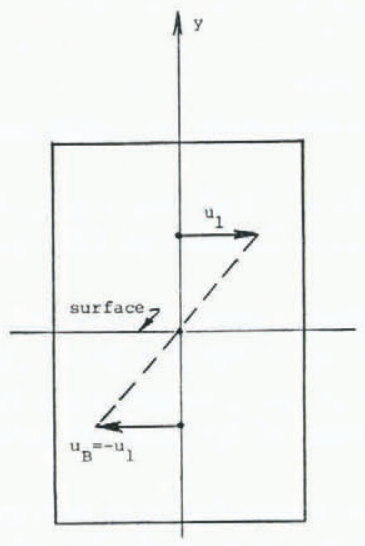

b) NO SLIP

$u_{s}=0$

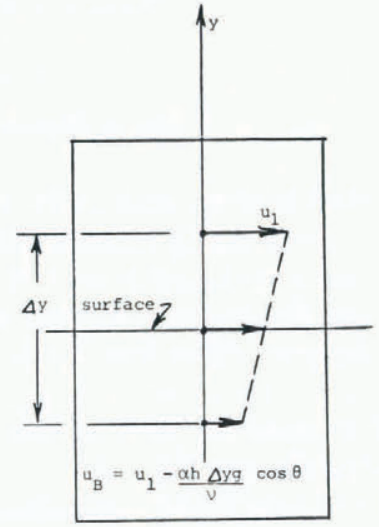

c) COULOMB FRICTION $u_{s}=\frac{u_{1}+u_{B}}{2}$

Fig. 3. Boundary velocity profiles for different surface velocities $u_{\mathrm{s}}$.

For modeling snow flow, a condition between free-slip and no-slip must be inserted at the lower fluid boundary. Snow does exhibit slippage at this surface, but this slippage is not drag free. A frictional force controls the rate of slipping. A model for this frictional force is part of the investigation reported in this paper.

In order to put a frictional force into the SMAC model, a relationship between force at the wall and velocity gradient must be established. This is required because specification of boundary-cell velocities is the method in which SMAC expresses the tangential boundary condition. The fundamental relationship that is used to do this is that the fluid shear stress is proportional to the velocity gradient in the fluid. The shear stress can then be related to a friction force and the velocity gradient can be specified by setting the boundary-cell velocity. For example, the first friction law considered was Coulomb, or dry, friction, where friction force $F$ is given by

$$
F=\alpha \mathcal{N},
$$

where $\alpha$ is the kinetic coefficient of friction and $\mathcal{N}$ is the normal force. For a material with surface area $A$ on a straight slope inclined at an angle $\theta, \mathcal{N}$ can be written as

$$
\mathcal{N}=\rho A h g \cos \theta,
$$


where $\rho$ is the density of the material, $h$ is its slope-normal depth, and $g$ is the acceleration of gravity. Equation (I) then becomes

$$
F=\alpha \rho A h g \cos \theta .
$$

The frictional surface stress, force per unit area, is then given by

$$
\frac{F}{A}=\alpha \rho h g \cos \theta .
$$

If the fluid is assumed to extend into the boundary cell, the average fluid shear stress $\tau$ between these two cells may be calculated from the velocity gradient, $\partial u / \partial y$ at the wall

$$
\tau=\mu \frac{\partial u}{\partial y} .
$$

Here $\mu$ is the dynamic coefficient of viscosity, $u$ is the horizontal velocity, and $y$ is the vertical coordinate. The average velocity gradient at the boundary wall can be written

$$
\frac{\partial u}{\partial y}=\frac{u_{\mathrm{I}}-u_{\mathrm{B}}}{\Delta y}
$$

where $u_{\mathrm{I}}$ is the flow velocity in the first cell, $u_{\mathrm{B}}$ is the boundary-cell velocity, and $\Delta y$ is the distance between the centers of the cells (Fig. $3 \mathrm{c}$ ).

If the fluid shear stress at the wall is equated to the frictional surface stress the following equation results

$$
\mu\left(\frac{u_{\mathrm{I}}-u_{\mathrm{B}}}{\Delta y}\right)=\alpha \rho h g \cos \theta .
$$

The boundary-cell velocity necessary for equality between the two stresses is found by solving Equation (4) for $u_{\mathrm{B}}$

$$
u_{\mathrm{B}}=u_{\mathrm{I}}-\frac{\alpha h \Delta y g \cos \theta}{\nu},
$$

where the kinematic viscosity $\nu$ has been substituted for $\mu / \rho$.

In a similar manner, the boundary-cell velocities may be computed for other forms of the friction force.

\section{Modeling THE SNOW TEST DATA}

In addition to requiring a firction law, with its attendant coefficient, another independent parameter, the kinematic viscosity, must also be specified as input to the SMAC computer code. Modeling the snow tests described earlier consisted of choosing a friction mechanism, then varying the friction coefficient and the kinematic viscosity to get correspondence between model and test.

The main criteria used in comparing model and test were the variation of the position of the leading edge with time and terminal debris-depth distribution. Although friction and viscosity interacted it was found that run-out distances were primarily dependent upon friction, whereas viscosity was the predominant factor which affected the debris depth.

\section{THE FRICTION FORCE}

First it was necessary to determine the type of friction force. The snow tests at higher speed ( $18 \mathrm{~m} / \mathrm{s}$ ) were chosen to model initially. Using SMAC, a continuous inflow condition was used to model the inflow of snow into the run-out area. Fluid $0.20 \mathrm{~m}$ deep was input into the flow domain for $0.4 \mathrm{~s}$ with inflow velocity decreasing linearly from $18 \mathrm{~m} / \mathrm{s}$ to $16 \mathrm{~m} / \mathrm{s}$ during the interval. This resulted in fluid flow of length 6.7 to $6.9 \mathrm{~m}$, depending on the 
friction being used. For the run-out zone SMAC was set up with 120 cells, $0.2 \mathrm{~m}$ wide, to represent a $24 \mathrm{~m}$ run-out. Vertically 6 cells, $0.05 \mathrm{~m}$ high, were used, with fluid inflowing the bottom four cells. The viscosity was adjusted to give the correct terminal debris depth.

The first friction force to be tested was Coulomb friction (Equations ( 1 ) and (2)). Inaho (I94I) determined experimentally that the kinetic coefficient of friction for granular snow blocks sliding on granular snow varied between 0.42 and 0.62 . Perla and others (unpublished) put the value of the kinetic friction coefficient between 0. 8 and 0.50 . For a friction coefficient of 0.7 , SMAC calculated the velocity of the leading edge of the flow to be $5.1 \mathrm{~m} / \mathrm{s}$ after the snow had run through the entire $24 \mathrm{~m}$ run-out area. Clearly the friction force was too small. Rather than going to an unreasonably high value of the kinetic coefficient of friction, another type of friction force must be in operation.

In the next test it was assumed that the friction force was linearly proportional to the slip velocity. But this form of the frictional force could not bring the snow to a stop, since at low speeds the force becomes negligible. Next it was proposed that the friction force be the sum of a Coulomb friction term and a term proportional to the slip velocity $u_{\mathrm{s}}$, i.e.

$$
F=\alpha \mathcal{N}+\beta u_{\mathrm{s}} \text {. }
$$

This friction force has two coefficients. However, if use is made of the test data on terminal velocity the two coefficients can be related. At terminal velocity a steady state is achieved where the friction force and the force of gravity are in equilibrium. Equating the equilibrium driving force $m g \sin \theta$ to the friction force $F$, and solving for the coefficient $\beta$ gives

$$
\beta=\frac{m g}{u}(\sin \theta-\alpha \cos \theta) \text {. }
$$

Recalling that it was found that on a $42^{\circ}$ slope, the terminal velocity of snow o.I $2 \mathrm{~m}$ deep was $u=6 \mathrm{~m} / \mathrm{s}$, substitution of these values into Equation (7) results in a relationship between $\alpha$ and $\beta$.

When this friction force is used in SMAC, a value of $\alpha=0.5$ resulted in the closest correspondence with the snow test data. With this coefficient, a total run-out distance of $21.6 \mathrm{~m}$ after $2.6 \mathrm{~s}$ was computed. This compares with a run-out of $22.3 \mathrm{~m}$ after $2.4 \mathrm{~s}$ for the snow test. Figure 4 is a plot of the position of the leading edge versus time for the model and for the snow test. Now, if $\alpha$ is increased, $\beta$ decreases, and high-speed retardation is reduced while low-speed friction is increased. Similarly, decreasing $\alpha$ results in less low-speed friction and more high-speed friction. Changing the viscosity also has an effect on the run-out distance. As viscosity is increased, more energy is dissipated internally, resulting in decreased run-out distances and speeds.

Over the speed range covered $(0-18 \mathrm{~m} / \mathrm{s})$ the correspondence between model and test is good, however it is probable that for higher velocities the frictional retardation would not be strong enough. This is based on the observation (Voellmy, I955; Schaerer, [1975]) that the terminal velocity of an avalanche may be described by the equation

$$
u_{\max }=[\xi h(\sin \theta-\alpha \cos \theta)]^{\frac{1}{2}},
$$

whereas a friction force given by Equation (6) results in a terminal velocity given by

$$
u_{\max }=\xi h(\sin \theta-\alpha \cos \theta),
$$

which establishes too strong a dependence upon the parameters $h, \alpha$, and $\theta$. In these equations $\xi$ is a coefficient of dynamic drag, $\theta$ is the slope angle, $h$ is the flow depth, and $\alpha$ is the kinetic coefficient of friction.

Equation (8) results from a retardation force assumed proportional to the square of the velocity. Thus a friction force of the form

$$
F=\alpha \mathcal{N}+\beta u_{\mathrm{s}}^{2},
$$




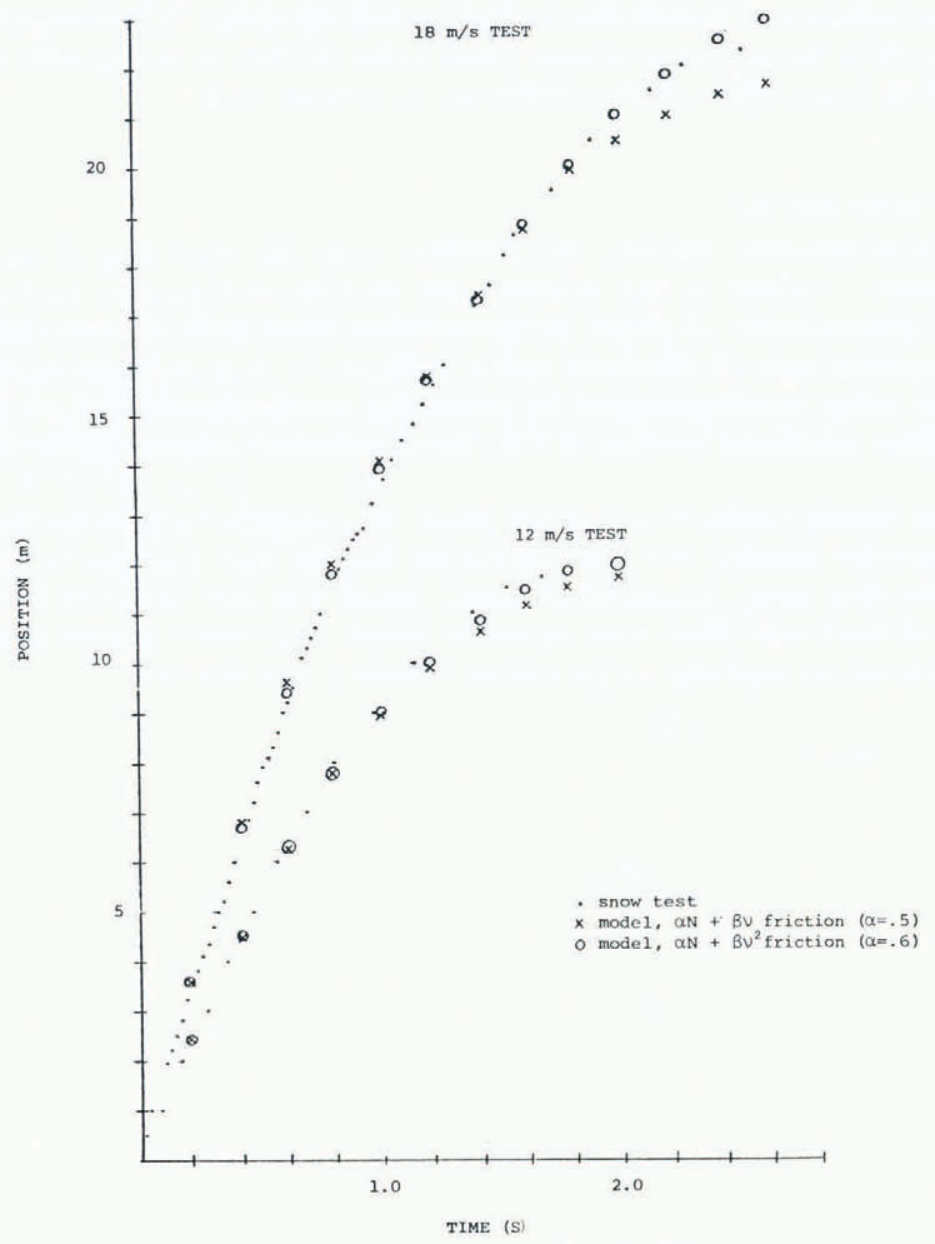

Fig. 4. Leading-edge position versus time.

was tried next. Again the terminal velocity data, $u=6 \mathrm{~m} / \mathrm{s}, \theta=42^{\circ}$, and $h=0.12 \mathrm{~m}$, were used to eliminate one of the coefficients from Equation (9),

$$
\beta=\frac{m g}{u^{2}}(\sin \theta-\alpha \cos \theta) .
$$

When Equation (9) is used in SMAC, the best fit to the data is obtained for $\alpha=0.6$. In modeling the $18 \mathrm{~m} / \mathrm{s}$ snow test a total run-out of $22.9 \mathrm{~m}$ was calculated to take place in $2.6 \mathrm{~s}$. The position of the leading edge versus time for this model is plotted in Figure 4. Also in Figure 4, the position of the leading edge versus time for the slower $12 \mathrm{~m} / \mathrm{s} \mathrm{snow} \mathrm{tests} \mathrm{is}$ plotted along with that for the model in which friction varies linearly with velocity $(\alpha=0.5)$ and that in which it varies as $u^{2}(\alpha=0.6)$.

The extra run-out, and the seemingly high values of the kinetic coefficient of friction $\alpha$, may be explained in part by the use of the constitutive law for a Newtonian fluid. As modeled, the fluid will not support a shear stress without deformation. Snow, however, does tend to lock up as the shear stress reaches some minimum value. This locking of the snow takes place 
mainly at low velocities and causes the motion to stop abruptly. The computer model, not being able to simulate this property of snow, must bring the flow to a stop using kinetic friction. Thus, a somewhat larger value of the coefficient $\alpha$ must be used.

\section{Viscosity AND FLOW PROFILE}

The interaction between viscosity and friction made the modeling of the snow tests an iterative procedure. Values of the friction and viscosity coefficients had to be adjusted relative to each other in order to satisfy the flow criteria taken from the snow tests. The results in the previous section were all obtained with a value of $\nu=0.04 \mathrm{~m}^{2} / \mathrm{s}$ for the kinetic viscosity coefficient. This value was determined by matching the distribution of the terminal debris depth with position calculated by SMAC with the distribution taken from the film of the snow test.

The terminal debris profiles were found from the computer model by freezing the flow when the slip velocity became zero. It was found that the rear portions of the flow stopped first, while the leading edge continued to move, which was also observed in the snow tests. As each section of the model flow came to rest its height and position were noted, in this way a profile of depth versus position, as plotted in Figure 5, was derived.

SNOW TEST

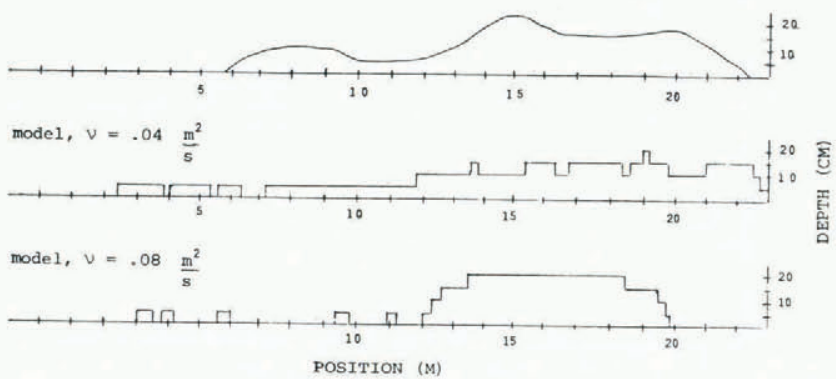

(a) $18 \mathrm{~m} / \mathrm{s}$ TERMINAL DEBRIS

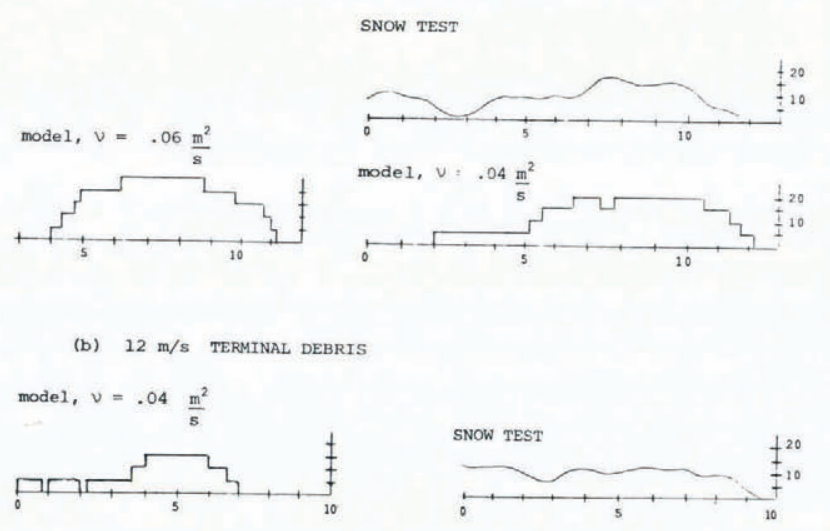

(c) $10 \mathrm{~m} / \mathrm{s}$ HALF DUMP TERMINAL DEBRIS

Fig. 5. Terminal debris depth versus position. 
The tails in the test-flow debris were caused by snow trailing the main part of the test. This snow came down after the main flow had stopped and was deposited at the end of the debris. Since the camera frame would not cover the full $24 \mathrm{~m}$ run-out, the exact amount of this deposition was not known. Therefore the entire debris pile was plotted.

Using the law in which friction is proportional to $u^{2}(\alpha=0.6)$, computer models of the various snow tests were made. Figure 5 a shows the terminal depth distribution for the $18 \mathrm{~m} / \mathrm{s}$ snow test and model results with $\nu=0.04 \mathrm{~m}^{2} / \mathrm{s}$ and $\nu=0.08 \mathrm{~m}^{2} / \mathrm{s}$. Figure $5 \mathrm{~b}$ shows the results of modeling the $12 \mathrm{~m} / \mathrm{s}$ flow tests, and Figure $5 \mathrm{c}$ compares the model results to the half load $10 \mathrm{~m} / \mathrm{s}$ test. In general, it can be seen that the lower viscosity coefficients resulted in shallower debris depths and more extensive spreading of the flow.

The window tests afforded a view into the profile of velocity with depth. Data from five window tests are plotted as a composite in Figure 6a. Also shown in Figure 6a are a linear and a quadratic least-squares fit to the data. In Figure $6 \mathrm{~b}$ corresponding model velocity profiles after the test has running for $0.4 \mathrm{~s}$ and $0.6 \mathrm{~s}$ are plotted. These times are the approximate time range during which the experimental data were gathered. These velocities are calculated at a point $3.0 \mathrm{~m}$ into the flow where the center of the glass window was located. The quadratic least-squares fit to the profile of velocity versus depth is matched closely by the computer model and most of the experimental points are within the two profiles plotted.
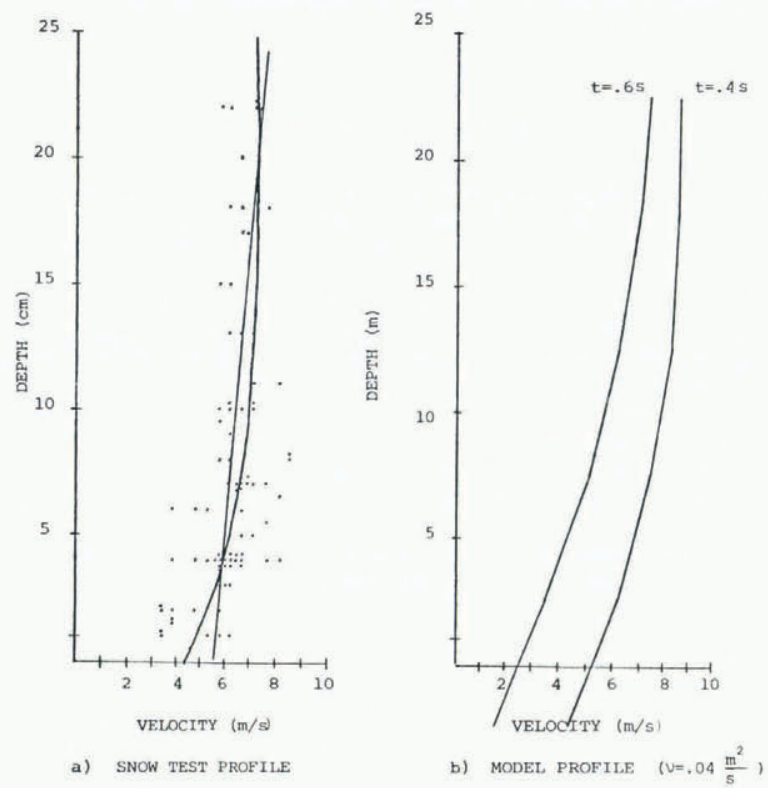

Fig. 6. Velocity profile versus depth.

\section{Conclusions}

For all the dump snow tests, the correspondence between model and test is quite good, both for the linear and the $u^{2}$ friction mechanisms. The $u^{2}$ friction mechanism is preferred, however, since this correlates better with previous work, which indicates that resistive forces are of this nature.

The biggest discrepancy between test and model occurs for the half load, $10 \mathrm{~m} / \mathrm{s}$ case. The snow test ran a total of $9.4 \mathrm{~m}$ while the model stopped at $7 \mathrm{~m}$. Also, in the model, snow did not spread horizontally as much as in the test, and the terminal depth is too deep in the model. These differences could all be corrected by reducing the viscosity coefficient in SMAC. 
This presents the possibility that the model viscosity may depend on flow. In particular that the viscosity coefficient increases as the depth of the flow increases. This is in line with the results of Lang and others (1979), in which another computer model of fluid flow is used to simulate full-size avalanches.

The tests and modeling reported in this paper were very limited, being loose snow flows $20 \mathrm{~cm}$ deep and slower than $20 \mathrm{~m} / \mathrm{s}$. Clearly we, as authors, feel that the flow mechanisms observed in these tests are representative of some types of full-scale avalanches. However, this can only be hypothesis until more data on the flow of large avalanches can be obtained. For the small flows studied, the computer model developed gives reasonable representations for the flows observed.

\section{Acknowledgement}

The authors wish to acknowledge the continued support for this work by Dr M. Martinelli, Jr, Group Leader for snow research at the Rocky Mountain Forest and Range Experiment Station, Fort Collins, Colorado (Agreement No. I6-884-CA), and Professor Theodore Williams, Department Head, Civil Engineering and Engineering Mechanics, Montana State University, Bozeman, Montana. Assistance with the collection of field data was provided by Mr Duain Bowles, Mr John Hightower, and Mr Edward Adams.

\section{REFERENGES}

Amsden, A. A., and Harlow, F. H. 1970. The SMAC method: a numerical technique for calculating incompressible fluid flows. Los Alamos Scientific Laboratory. Report No. LA-4370.

Inaho, Y. I941. Sekisetsu no dō-masatsukaku ni tsuite [Angle of kinetic friction of snow]. Seppyō, Vol. 3, p. $303-07$.

Lang, T. E., and others. 1979. Numerical simulation of snow avalanche flow, by T. E. Lang, K. L. Dawson, and M. Martinelli, Jr. U.S. Dept. of Agriculture. Forest Service. Research Paper RM-205.

Perla, R. I., and others. Unpublished. Avalanche motion, by R. [I.] Perla, T. T. Cheng, and D. M. McClung. [Paper presented at the first Annual National Conference on Recreation Planning and Development, Snowbird, Utah, i8-21 April r979.]

Schaerer, P. A. [1975.] Friction coefficients and speed of flowing avalanches. [Union Géodésique et Géophysique Internationale. Association Internationale des Sciences Hydrologiques. Commission des Neiges et Glaces.] Symposium. Mécanique de la neige. Actes du colloque de Grindelwald, avril 1974, p. 425-32. (IAHS-AISH Publication No. I14.)

Voellmy, A. 1955. Über die Zerstörungskraft von Lawinen. Schweizerische Bauzeitung, Jahrg. 73, Ht. 12, p. I $59-62$; Ht. I5, p. 2 1 2-1 7; Ht. I 7, p. 246-49; Ht. I9, p. $280-85$. 